\title{
Experimenting E-Learning for Postgraduate Courses
}

\author{
http://dx.doi.org/10.3991/ijet.v11i04.5559
}

\author{
Ali H. Al-Marzouqi and Waleed K. Ahmed \\ United Arab Emirates University, Al Ain, UAE
}

\begin{abstract}
E-learning pedagogy is one of the most recent methods used by instructors at the undergraduate level at the colleges worldwide. Students benefit from e-learning instruction by having a better grasp of information. In the present work, e-learning was used in a postgraduate course in the College of Engineering at UAE University to motivate students in educational materials required for Chemical Engineering Department. The initiative started after a successful experience in an undergraduate course. Therefore, the present research was done as an attempt to replicate the study and test it for postgraduate courses. All students were asked to submit assignments in the shape of e-learning to produce educational materials on different course topics. The collected and analyzed feedbacks showed that students have interesting ideas and approaches to reach the desired target. This experience revealed positive response as well as the potential to many promising aspects that can be used in the future to develop similar assignments for the enhancement of student's knowledge.
\end{abstract}

Index Terms-E-learning, video, project, chemical, postgraduate.

\section{INTRODUCTION}

The revolution of computer technologies as well as the internet has their impressive impact on our life by all means and standards, whether in its positive or negative consequences. However, using these technologies can be so positive once adopted in the right way especially in the educational sector. Implementing educational e-learning in pedagogy has been under investigation to boost outcomes especially for the undergraduate education, whether in term of individual or collaborative learning. On the other hand, adopting e-learning for the postgraduate courses has witnessed a progressive development in this direction, especially in the engineering education. Learning is a process of acquiring and synthesizing ideas and concepts. The process not only involves obtaining information but also full participation by the learner (studentcentered learning) [1]. Ahmed and Zaneldin [2] presented a diverse learning technology for teaching pre-engineering freshman students using Blackboard and new classroom technologies. Other works have utilized video technologies, for example, Liberatore [3] has utilized YouTube to relate course topics to real-world applications. Falconer et al. [4] have compiled screencasts where a narrator goes over a particular chemical engineering concept or a detailed problem solution. Green et al. [5] stated that students who use screencasts and perceive their benefit have better results on exams. Abulencia et al. [6], discussed the teaching of concepts in an introductory thermodynamics course through video, considering that this generation of students is technology savvy, and regularly communicates by means other than face-to-face interactions. Ahmed and Al-Marzouqi [7] used blended learning as a tool for enhancing the students' perceptive for undergraduate engineering thermodynamics course. In that study produced materials were distributed to the students through a website as well as via YouTube. According to Moron-Garcia [8], the use of technology can facilitate the creation of student-centered learning environment. Student-centered learning and learning environments designed with reference to constructivist theories of learning will produce in students the critical and cognitive skills that higher education aims to develop. It has been observed that collaborative learning is a key component in a variety of didactical strategies, attracts attention because of its potential as a powerful strategy to foster learning. Collaborative learning is a process by which individuals negotiate and share meanings relevant to the problem-solving task at hand. In collaborative learning, students work together in small clusters to attain joint learning ends [9]. On the other hand, adequate ICT tools that support both traditional and emerging engineering education have been developed which deliberates upon the applications of e-learning and its current practice in engineering education [10]. In a collaborative and autonomous way, Martín-Gutiérrez et al. [11] combine every learning process from the Electrical machines course in the electrical engineering degree. This allowed interactive and autonomous studying as well as the collaborative performance of laboratory practices with other students and without a teacher's assistance. Tools presented in this work achieved a connection between the theoretical explanations and the laboratory practices using augmented reality as a nexus. Another study assessed elearning tools for the mechanisms of action of chemotherapy drugs, and the subsequent effects on learning in two cohorts (control and intervention) of undergraduate pharmacy students [12]. The intervention group had access to the e-learning tools in addition to the traditional didactic teaching delivered to the control group. The structure of the Observed Learning Outcome (SOLO) taxonomy was used to classify students' exam responses. Nowadays, we are immersed in the social and mobile networks era [13]. As a positive consequence of this, collaborative and mobile learning in educational environments has been encouraged thanks to the use of computing for human learning. By coupling the advantages of collaborative and mobile learning, the teaching-learning processes involved in postgraduate courses may be greatly enhanced. In engineering, chemistry is considered as a difficult and boring subject [14]. Some professors who are teaching chemistry, have seen apathy and lack of interest in the students. Some investigations have allowed listening to the voice of 250 
Mexican students regarding the usefulness of cooperative learning in chemistry. An exploratory-descriptive methodology was applied, together with a pretest and a posttest discussion. By implementing the Cooperative Learning, the importance of the positive interdependence for critical thinking was appraised and a move away was detected from the theoretical content and meaning of the everyday context of the students. Due to rapid technological progress, the world of education is continuously changing. In recent decades, the use of the Internet, together with new information and communication technologies, has become an important component of teaching/learning strategies in universities [15]. Today, eLearning has become a viable alternative to traditional methods, and adopted by many educational institutions, especially because of the advantages offered by the possibility of continuous training. E-learning in higher education can be of great relevance ineffective life-long learning education for sustainable development in a population of students who are simultaneously full-time employees [16]. The availability of $3 \mathrm{G}$ and $4 \mathrm{G}$ technologies coupled with tablet PCs and smartphones makes the communication and learning system easier [17]. In engineering education, these sophisticated technologies can bring immense advantages to the methods of delivering and acquiring knowledge. Facilities of a smart class environment for engineering education that can improve the co-learning procedure has been used tremendously, in particularly emphasizing the use of $3 \mathrm{G}$ and $4 \mathrm{G}$ technology in a smart class. Cloud E-learning for Mechatronics (CLEM) is an example of a domain-specific cloud that is specially tuned to the needs of VET (Vocational, Education, and Training) teachers [18]. An interesting development has been the creation of remote laboratories in the cloud. Learners can access such laboratories to support their practical learning of mechatronics without the need to set up laboratories at their own institutions. The cloud infrastructure enables multiple laboratories to come together virtually to create an ecosystem for educators and learners. From such a system, educators can pick and mix materials to create suitable courses for their students and the learners can experience different types of devices and laboratories through the cloud.

In this study, a postgraduate program was chosen to implement the e-learning methodology in a collaborative way, where nominated projects were distributed to students. Material developed by the students were collected and evaluated. A survey was conducted to assess the experience gained by the students and the results were analyzed and discussed.

\section{Post Graduate StUdies In CHEMICAL ENGINEERING}

The goal of this program is to graduate master-level chemical engineers who are highly qualified for a rewarding professional experience. Graduates may choose to work in the chemical, petrochemical, biochemical or other related industries, continue on to other graduate level degrees, or join consulting/contracting companies. Prospective students have to be motivated to seek life-long learning and professional development and be capable of becoming professionals and leaders in the global industries. The Program Objectives are summarized below:
- To generate graduates with high levels of competence in fundamental and applied concepts of chemical engineering.

- To provide opportunities to address industrially important problems and to propose and investigate possible solutions.

- To provide an environment in which students can embrace social and personal development.

- To motivate the students to seek life-long learning and professional development.

- To enhance students recognition and understanding of the professional and societal responsibilities associated with working in the industry.

- To develop computational techniques, and written and oral communication skills.

- To cultivate innovation and entrepreneurship through a deeper understanding and advanced knowledge of the Chemical Engineering principles and operations.

\section{A. Program Learning Outcomes}

Upon successful completion of this program, students will be able to:

Apply advanced concepts of fundamental sciences and engineering to solve complex Chemical Engineering problems.

- Demonstrate the ability to work effectively both independently and in teams of various backgrounds.

- Apply innovative and practical solutions to existing or novel processes in research.

- Search, evaluate and acquire information from relevant chemical engineering literature.

- Design advanced approaches to conducting chemical engineering experiments.

- Use advanced quantitative and qualitative methods to interpret research experimental results.

- Disseminate and discuss their professional and scientific work to the general public, as well as to experts in both writing and oral formats.

- Observe and apply ethical and professional codes and responsibilities.

In this study, Advanced Reaction Engineering (CHME612) course was selected to explore the impact of the collaborative e-learning on the students' performance. The course covers the following subjects: Kinetics of fluid-solid reactions in single particles, Mechanisms and kinetics of catalytic reactions; Reactor design: Fixed, fluidized and transport bed reactors for homo/heterogeneous systems; Novel reactors; Applications in petroleum and chemical industries.

\section{THE PROJECT}

The idea of the project was delivered to the students at the beginning of the semester through a list of topics that were related to the material covered in the course. These topics were:

1. Rate laws and stoichiometry.

2. Performance equations, reactor sizing.

3. Catalysis and catalytic reactors, synthesizing a rate law, mechanism and rate limiting step. 
4. Catalyst deactivation, moving bed reactors, straightthrough transport reactors.

5. External diffusion effects on heterogeneous reactions, binary diffusion.

6. Mass transfer limited reactions in packed beds, shrinking core model.

7. Diffusion and reaction in spherical catalyst pellets.

8. Mass transfer and reaction in packed beds.

9. Multiphase reactors.

10. Distributions of Residence Times for Chemical Reactors.

In general, the students were free to choose their subjects, so as consequence, the following topics were selected by the students:

1. Rate laws and stoichiometry

2. Performance equations, reactor sizing

3. Catalysis and catalytic reactors, synthesizing a rate law, mechanism and rate limiting step

4. Catalyst deactivation, moving bed reactors, straightthrough transport reactors

5. Diffusion and reaction in spherical catalyst pellets

6. Multiphase reactors

The aim of the project was to encourage students to establish a collaborative work covering the course material using e-learning to be considered as an extra bonus for the students. Besides, the developed material was deployed among the students to enhance their knowledge. A deadline for the projects submission was decided to be the end of the semester. A survey was prepared for this activity and distributed after collecting the accomplished projects. Table 1 lists the questions that were answered by the students.

\section{RESUlts AND Discussion}

This experience showed the unexpected potential of students to participate in this activity, where they selected their projects by themselves and started to search for the technology to produce the idea for their topic in an educational manner. Students were guided and advised during the development of their projects in term of scientific contents as well as the presentation style of the information. Some samples of the accomplished projects are illustrated below in Figure 1. As a matter of fact, the general impressions were positive from the students, although is added a little pressure on them since construction such kind of assignment is faced for the first time in their study, especially in this particular level, but the experience was a challenge for them, so they took this challenge seriously nd produced unexpected outcomes for the subjects that they selected.

TABLE I.

QUESTIONS THAT WERE ANSWERED BY THE STUDENTS.

\begin{tabular}{|c|c|c|c|c|c|c|}
\hline & & \\
\hline & & SA & A & $\mathbf{N}$ & D & SD \\
\hline 1 & I like my selected topic. & $40 \%$ & $40 \%$ & $0 \%$ & $0 \%$ & $10 \%$ \\
\hline 2 & I think the materials in the video are similar to those presented in the lecture. & $40 \%$ & $40 \%$ & $20 \%$ & $0 \%$ & $0 \%$ \\
\hline 3 & My video will help the level of students understanding of the topic. & $40 \%$ & $20 \%$ & $40 \%$ & $0 \%$ & $0 \%$ \\
\hline 4 & I have added one or more unsolved questions in the video for students to try solving by themselves. & $0 \%$ & $60 \%$ & $0 \%$ & $40 \%$ & $0 \%$ \\
\hline 5 & I believe that the video is good enough to be understood. & $20 \%$ & $60 \%$ & $0 \%$ & $20 \%$ & $0 \%$ \\
\hline 6 & If no grade/bonus is given, I will not participate in doing a video in the future. & $40 \%$ & $0 \%$ & $0 \%$ & $20 \%$ & $40 \%$ \\
\hline 7 & $\begin{array}{l}\text { I am not interested in developing videos for Advanced Reaction Engineering course, it is a waste of } \\
\text { time. }\end{array}$ & $0 \%$ & $0 \%$ & $40 \%$ & $20 \%$ & $40 \%$ \\
\hline 8 & Well prepared videos will help students to understand the subject better. & $20 \%$ & $40 \%$ & $20 \%$ & $20 \%$ & $0 \%$ \\
\hline 9 & I will encourage my colleagues in other courses to develop videos for their course topics. & $20 \%$ & $40 \%$ & $40 \%$ & $0 \%$ & $0 \%$ \\
\hline 10 & I like someone to teach me how to create educational videos. & $0 \%$ & $60 \%$ & $20 \%$ & $20 \%$ & $0 \%$ \\
\hline 11 & The software used is very good and easy to use. & $20 \%$ & $40 \%$ & $20 \%$ & $20 \%$ & $0 \%$ \\
\hline 12 & The created video can be modified. & $40 \%$ & $20 \%$ & $0 \%$ & $40 \%$ & $0 \%$ \\
\hline 13 & I agree to use my video in future courses by the instructor. & $40 \%$ & $40 \%$ & $0 \%$ & $0 \%$ & $20 \%$ \\
\hline 14 & I don't like to participate in this questionnaire. & $20 \%$ & $0 \%$ & $40 \%$ & $0 \%$ & $40 \%$ \\
\hline 15 & I think that answering this survey will help improve the teaching of this course. & $40 \%$ & $40 \%$ & $20 \%$ & $0 \%$ & $0 \%$ \\
\hline
\end{tabular}

SD: Strongly Disagree, DIS: Disagree, N: Neutral, A: Agree, SA: Strongly Agree 

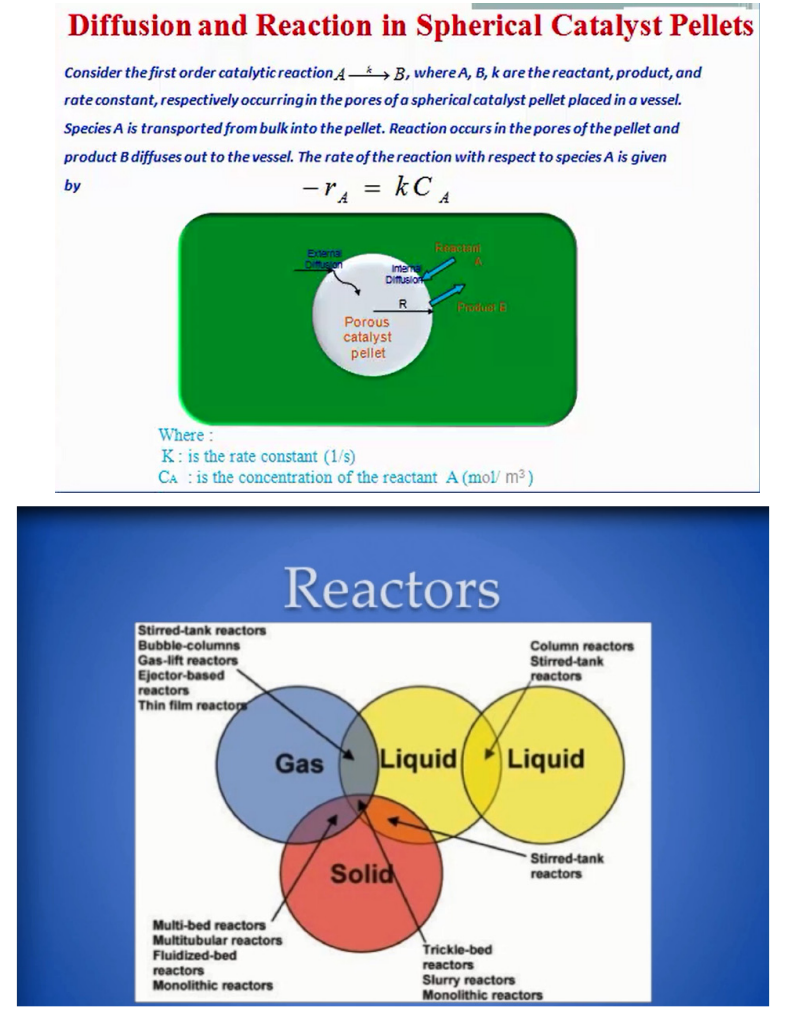

Samples of the students' projects.

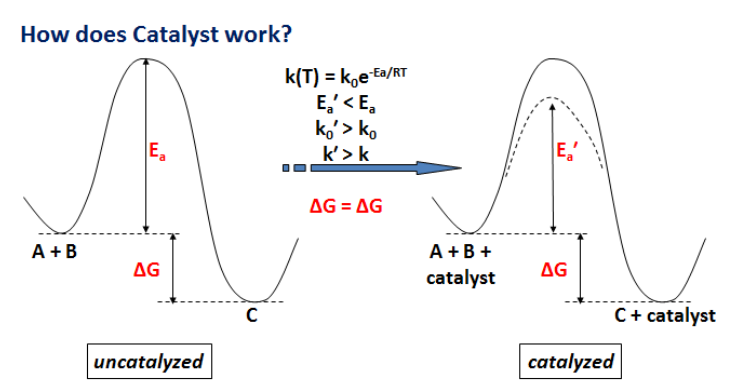

Catalyst changes the reaction rate by promoting a different reaction path, through decreasing the activation energy.

\section{Implications of Arrhenius Law}

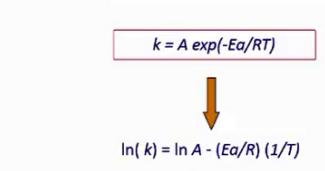

The activation energy is a theasure of how temperature sensitive the reaction is. Reactions with large activation energies are very temperature sensitive.

One can also write the specific reaction rate as: $k=k_{0} \exp \left[\frac{E}{R}\left(\frac{1}{T_{0}}-\frac{1}{T}\right)\right]$

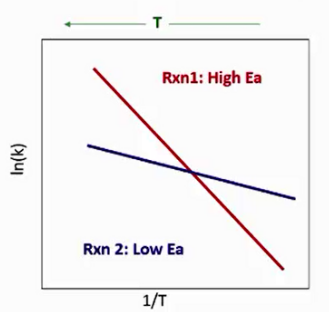

Once the projects were collected they were assessed. Meanwhile, the distributed survey was collected and analyzed. In general, around $80 \%$ of the students liked their selected projects, which reflects the wise choice of the topics by the students, and this steers the direction of the research in the right way, whereas only $10 \%$ did not like the project that they developed. About $80 \%$ of the students believed that the material they developed was similar to the one used by the lecturer, and this reflects the same aforementioned conclusions. Moreover, $60 \%$ of the students believe that their work will help the students of the course to increase their understanding level through their contribution, the remaining $40 \%$ have a neutral response. Students were encouraged to enhance their participation through some interactive material like questions or challenges, and $60 \%$ adopted this idea. It is important to mention that the students did their best to produce attractive work through using different technologies, starting from animations and ending with videos, which required big efforts from them. About $80 \%$ of the students think that the video used in their project will assist students for better understanding the topics of the course. On the other hand, $60 \%$ of students mentioned that they would not have participated in this activity if there was no bonus point. This is confirmed in question no. 7 , where only $40 \%$ believed that it was a waste of time, while $40 \%$ had a neutral opinion. Only $20 \%$ believe that well-prepared videos will not help the students understanding, 20\% neutral and 60\% agree in general that videos are useful. This reflects some hesitation about the objective of the project from the student's perspective. This is assured by the next question, which shows their unwillingness to advise the other students to develop videos, due to significant efforts required. Only $20 \%$ of the students did not need to be trained or helped to develop educational materials, whereas $60 \%$ did not have their own skills. It seems that $60 \%$ did not face any difficulties in using and production educational materials, $20 \%$ only weren't able to manage it. Regarding the technical part of the study, only $40 \%$ of the produced educational videos cannot be modified, whereas $60 \%$ can be. Due to the privacy issue, $80 \%$ of the students did agree that their projects to be used as educational material by the instructor of the course, but the remaining $20 \%$ did not agree. For the participation in the survey, $20 \%$ liked to participate, but $40 \%$ did not like it, and $40 \%$ had a neutral opinion. By answering the distributed survey, $80 \%$ have a positive answer that it will improve teaching the course.

\section{CONCLUSIONS}

In this research, an educational attempt was done and accomplished at the postgraduate level to enhance the teaching experience through involving students to produce educational material that will be assessed and evaluated for further bonus points. Through a survey that was designed and distributed to the students and, later on, was collected and analyzed, it has been observed that the atmosphere was positive in general. Many observations and conclusion may be used for further development.

\section{REFERENCES}

[1] L. Fowler, J. Armarego, and M. Allen, "CASE Tools: Constructivism and its application to learning and usability of software engineering tool," Computer Science Education, vol. 11, pp. 261-271, 2001. http://dx.doi.org/10.1076/csed.11.3.261.3835

[2] W.K. Ahmed, and E. Zaneldin, "E-Learning as a Stimulation Methodology to Undergraduate Engineering Students," International Journal of Emerging Technologies in Learning, vol. 8, no. 3, 2013. http://dx.doi.org/10.3991/ijet.v8i3.2550

[3] M.W. Liberatore, "YouTube Fridays: Engaging the Net Generation in Five Minutes a Week," Chemical Engineering Education, vol. 44 , no. $215,2010$. 
PAPER

\section{EXPERIMENTING E-LEARNING FOR POSTGRADUATE COURSES}

[4] J.L. Falconer, G.D. Nicodemus, J. DeGrazia, and J.W. Medlin, "Chemical Engineering Screencasts," Chemical Engineering Education, vol. 46, pp. 58-62, 2012

[5] K.R. Green, T. Pinder-Grover, and J.M. Millunchick, "Impact of Screencast Technology: Connecting the Perception of Usefulness and the Reality of Performance," Journal of Engineering Education, vol. 101, no. 4, pp. 717-737, 2012. http://dx.doi.org/10.1002/ j.2168-9830.2012.tb01126.x

[6] J.P. Abulencia, M.A Vigeant, and D.L. Silverstein, "Teaching Thermodynamics Through Video Media," 120th ASEE annual conference and exposition, Atlanta, GA, 2013

[7] W.K. Ahmed, and A.H. Al Marzouqi, "Using blended learning for self-learning," Int. J. Technology Enhanced Learning, vol. 7, no. $2,2015$.

[8] S. Moron-Garcia, "Using virtual learning environments: Lecturers' conception of teaching and the move to student-centered learning," Proceedings of the International Conference on Computers Education (ICCE'02), 2002. http://dx.doi.org/10.1109/cie. 2002.1186313

[9] A. Shahzad, M. Valcke, and R. Bahoo, "A study to analyze the teacher's perceptions about the adoption of collaborative learning in post-graduate classes of IUB," Procedia - Social and Behavioral Sciences, vol. 46, pp. $3056 \quad$ - 3059, 2012. http://dx.doi.org/10.1016/j.sbspro.2012.06.009

[10] M.T. Banday, M. Ahmed, and T.R. Jan, "Applications of eLearning in engineering education: A case study," Procedia - Social and Behavioral Sciences, vol. 123, pp.406 - 413, 2014. http://dx.doi.org/10.1016/j.sbspro.2014.01.1439

[11] J. Martín-Gutiérrez, P. Fabiani, W. Benesova, M.D. Meneses, and C.E. Mora, "Augmented reality to promote collaborative and autonomous learning in higher education," Computers in Human Behavior, vol. 51, pp. 752-761, 2015. http://dx.doi.org/10.1016/ j.chb.2014.11.093

[12] L. Baumann-Birkbeck, A. Karaksha, S. Anoopkumar-Dukie, G. Grant, A. Davey, S. Nirthanan, and S. Owen, "Benefits of elearning in chemo therapy pharmacology education,: Currents in Pharmacy Teaching and Learning, vol.7, pp.106-111, 2015. http://dx.doi.org/10.1016/j.cptl.2014.09.014

[13] I. López-Yáñez, C. Yáñez-Márquez, O. Camacho-Nieto, M. Aldape-Pérez, Amadeo-José, and Argüelles-Cruz, "Collaborative learning in postgraduate level courses," Computers in Human Behavior, vol. 51, pp. 938-944, 2015.

[14] M. Rodríguez, R. del C., B. Corona L., and V. Ibáñez M, “Cooperative learning in the implementation of teaching chemistry (didactic instrumentation) in engineering in México, "Procedia - Social and Behavioral Sciences," vol.174 pp. 2920 - 2925., 2015 http://dx.doi.org/10.1016/j.sbspro.2015.01.1029

[15] A. Simo, C. Barbulescu, and S. Kilyeni, "Current Practices in Elearning: A Case Study for Electrical Power Engineering in Higher Education," Procedia - Social and Behavioral Sciences," vol. 191, pp. 605 - 610, 2015. http://dx.doi.org/10.1016/j.sbspro.2015.04. 342

[16] U. M. Azeiteiro, P. Bacelar-Nicolau, F.J.P. Caetano, Sandra Caeiro, "Education for sustainable development through elearning in higher education: experiences from Portugal," Journal of Cleaner Production," vol. 106, pp. 308-319, 2015. http://dx.doi.org/10.1016/j.jclepro.2014.11.056

[17] A. A.Abdullah Alghamdi, M. Shorfuzzaman, M.Rawashdeh, M.S Hossain, and G. Muhammad, "Enhanced engineering education using smart class environment," Computers in Human Behavior, vol. 51, pp. 852-856., 2015. http://dx.doi.org/10.1016/j.chb.2014. 11.061

[18] K.-M. Chaoa, A. E. James, A. G. Nanos, J.-H. Chen, S.-D. Stan, Io. Muntean, G. Figliolini, P. Rea, C. B. Bouzgarrou, P. Vitliemov, J. Cooper, and J. van Capelle, "Cloud E-learning for Mechatronics: CLEM," Future Generation Computer Systems, vol.48, pp.46-59, 2015. http://dx.doi.org/10.1016/j.future.2014.10.033

\section{AUTHORS}

Ali H. Al-Marzouqi is with the Chemical and Petroleum Engineering Department, College of Engineering, United Arab Emirates University, Al Ain, UAE.

Waleed K. Ahmed is with the Engineering Requirements Unit, United Arab Emirates University, Al Ai, UAE.

Submitted 12 February 2016. Published as resubmitted by the authors 13 March 2016 